\title{
Colon Serrated Polyposis
}

National Cancer Institute

\section{Source}

National Cancer Institute. Colon Serrated Polyposis. NCI Thesaurus. Code C96470.

The presence of multiple serrated polyps in the colon. The polyps are predominantly sessile serrated adenomas/polyps. A minority of the polyps are microvesicular variants of hyperplastic polyps. According to some authors, the polyps are proximal to the sigmoid colon. According to others, the polyps are distributed throughout the entire colon. 